The Impact of Parents and Self-Selection on Child Survival among the Tsimane of Bolivia Author(s): Jeffrey Winking, Michael Gurven, Hillard Kaplan

Source: Current Anthropology, Vol. 52, No. 2 (April 2011), pp. 277-284

Published by: The University of Chicago Press on behalf of Wenner-Gren Foundation for Anthropological

Research

Stable URL: http://www.jstor.org/stable/10.1086/659334

Accessed: 31/03/2011 15:43

Your use of the JSTOR archive indicates your acceptance of JSTOR's Terms and Conditions of Use, available at http://www.jstor.org/page/info/about/policies/terms.jsp. JSTOR's Terms and Conditions of Use provides, in part, that unless you have obtained prior permission, you may not download an entire issue of a journal or multiple copies of articles, and you may use content in the JSTOR archive only for your personal, non-commercial use.

Please contact the publisher regarding any further use of this work. Publisher contact information may be obtained at http://www.jstor.org/action/showPublisher?publisherCode=ucpress.

Each copy of any part of a JSTOR transmission must contain the same copyright notice that appears on the screen or printed page of such transmission.

JSTOR is a not-for-profit service that helps scholars, researchers, and students discover, use, and build upon a wide range of content in a trusted digital archive. We use information technology and tools to increase productivity and facilitate new forms of scholarship. For more information about JSTOR, please contact support@jstor.org. 


\section{The Impact of Parents and Self-Selection on Child Survival among the Tsimane of Bolivia}

\section{Jeffrey Winking, Michael Gurven, and Hillard Kaplan}

Department of Anthropology, Texas A\&M University, College Station, Texas 77843-7352, U.S.A.

(jwinking@tamu.edu)/Department of Anthropology, University of California, Santa Barbara, California 93106-3210, U.S.A./Department of Anthropology, University of New Mexico, Albuquerque, New Mexico 87131, U.S.A. 11 XI 10

\section{CA+ Online-Only Material: Supplement A}

The impact of the parental investment provided by a mother or father on the well-being of a child depends on many factors. The effect of fathers is of particular theoretical interest, as there has been considerable debate concerning the importance of fathers in the evolution of our species and of our reproductive strategies involving long-term pair bonds and biparental care. A common strategy for investigating the impact that parents have on child outcomes is to compare children raised in households without a mother or father to those raised in households with both parents. There is question, however, as to what degree any such effects are simply the result of covarying mortality hazards within families or through time and not necessarily a direct impact of parental absence. Here we explore the issue of self-selection in our investigation of the effects of fathers and mothers on offspring survival among the Tsimane, a forager-horticultural population of central Bolivia. We find strong associations between mother death and child death, while father death has a lesser although still significant effect. We also show the potential for self-selection in parent-absence studies and the need to control for family effects.

Human parents are actively involved in the long-term rearing of their offspring. Children are often economically dependent on their parents for $25 \%-30 \%$ of their lives in societies as diverse as hunter-gatherers, farmers, and modern nationstates (Kaplan 1994; Lee and Kramer 2002). Despite this large investment in offspring, estimates of the net impact of parental presence on child welfare vary substantially cross-culturally (Sear and Mace 2008). A common technique for evaluating the importance of parents to the well-being of children has been to compare the outcomes of children from fatherless or motherless homes to those in which both parents are present. The difference is often referred to as a "father effect" or a "mother effect" and conceptualized as the impact that parents, and their investments, have on their children's survival,

(C) 2011 by The Wenner-Gren Foundation for Anthropological Research. All rights reserved. 0011-3204/2011/5202-0009\$10.00 DOI: 10.1086/ 659334 fertility, educational attainment, income, or other measures of well-being. Such studies have played a large role in illuminating the benefits of being raised in complete households and the costs of marital dissolution as well as informing debates concerning the evolution of humans' unique mating system and reproductive patterns.

Despite the strengths of using an alive/dead variable to uncover the full benefits (and occasionally costs) of parental presence, most studies fail to account for selection biases that may act to under- or overestimate true parent effects. One potentially substantial form of bias occurs if characteristics of the children, parents, or environments of incomplete households differ from those with both parents and if these factors also influence child outcomes. For example, a genetic susceptibility to disease or a spike in local rates of violence might elevate mortality risks for both parents and children, leading to a spurious association between parent and child mortality and an inflation of parental effects. Thus, any factors that are associated with the likelihood of parental death or divorce might result in differences in child outcomes between these two groups, independent of parental investment and its impacts.

We utilize demographic data of the Tsimane, a foraging/ horticulturalist population of central Bolivia, to explore the mother and father effects of Tsimane parents. Few studies have explored the impact of parental presence in subsistencelevel horticultural populations, particularly with the range of relevant information that has been collected on this population. To explore the impact of self-selection, we first ask whether the cause of parental absence affects the magnitude and direction of father and mother effects. If self-selection is a significant problem, we should find that the cause of parental and child deaths are associated and be able to determine whether certain causes of parental loss are more or less suited to such studies. Second, we examine whether the death of a parent is associated with a greater mortality risk for children before parental death. If shared environment, condition, and/ or behavioral trends lead to a general association in mortality rates among family members, then there should be no order effect. Parental death should be predictive of child death both before and after the event. We report that parent effects are found regardless of order but that controlling for family eliminates the effect of parental death on previous child mortality. This suggests that there exists between-family self-selection; however, this self-selection is not due to temporally varying factors but conditions that are experienced by the family as a whole.

\section{A Brief History of Parent Effect Studies}

Infants in subsistence societies are primarily dependent on breast milk until at least 6 months of age, at which time weaning foods are introduced. The timing of complete weaning varies substantially across and within populations but often entails an additional 1.5-2 years (Sellen and Smay 2001). 
While the responsibilities of nursing are shared in a few populations (Tronick, Morelli, and Winn 1987), breast-feeding responsibilities are less easily distributed among other kin upon the loss or desertion of the mother. All studies that have explored mother effects among natural fertility populations report significant impacts of mother absence on child mortality in the first years of life (Sear and Mace 2008). In preindustrial populations, the reported survival rates of infants who lose their mothers in the first year ranges from $1.6 \%$ in a nineteenth-century Swedish population (Hogberg and Brostrom 1985) to $50 \%$ in a Burkina Faso population (Becher et al. 2004). Such effects are less frequently found when mother death occurs later in the child's life.

Studies of father absence have a long history in the fields of psychology and family studies. Researchers originally sought to map the negative effects of father abandonment on the psychological, cognitive, and behavioral profiles of Western children (reviewed in Lamb 1997). Starting with Hurtado and Hill (1992), evolutionary-oriented researchers began exploring father effects to shed light on the potential fitness pathways that may have led to the development of universal pair bonds, and biparental care (Blurton Jones et al. 2000; Leonetti et al. 2004; Sear et al. 2002). The greater dependency of human offspring might have provided sufficiently high returns to paternal investment to make such investment preferable to alternative reproductive strategies. If so, it is argued, there should be substantial effects of father absence on child well-being, as fatherless children lose a substantial source of investment. Among natural fertility populations, father absence has been found to be significantly associated with higher child mortality in only two of four hunter-gatherer populations and five of 18 horticultural populations (for references, see Sear and Mace 2008). Few studies have explored the effects of parental absence on continuous outcomes of child wellbeing in such societies, and those that have report mixed results (Hagen et al. 2001; Hames, Oliver, and Chagnon 2005; Sear, Mace, and McGregor 2000).

\section{Self-Selection}

Despite the convenience of using dichotomous measures of presence/absence to measure parental investment, there are dangers in its use. The strategy assumes that the two groups are randomly selected with regard to other confounding factors or that these can at least be statistically controlled. There are two major sources of selection bias. The first source of bias is the ability and willingness of alternative caretakers to fill the gap left by a missing parent. If other caretakers increase investment on the loss of a parent, this can lead to underestimates of effects. The likelihood of such compensation might vary by how easily the lost investment can be substituted by other interested kin members. Any compensatory reactions, however, represent a true bias only if the parent effect is conceptualized as a proxy for parental investment. If the parent effect is conceptualized as the overall fitness benefit to staying within a long-term relationship and family involve- ment, then it is appropriate to assess outcomes without controlling for such compensation.

The more problematic form of self-selection bias occurs if characteristics of the children, parents, or environments of incomplete households differ from those with both parents and if these factors also influence child outcomes. Most studies make some attempt to control for group variables that might affect both the probability of parental absence and child outcomes (e.g., socioeconomic status). However, it is the individual characteristics that are more difficult to assess (e.g., genetic immunocompetence). Studies that control for family are able to remove much of the effect of self-selection, but this approach fails to take into account the temporal nature of many of the effects.

Studies investigating divorce in the United States tend to report relationship problems as the most common cause of divorce (e.g., a loss of love or differing values; Amato and Previti 2003; Kitson, Babri, and Roach 1985). Beyond these reasons, the most commonly reported causes include infidelity, financial problems, drug and alcohol abuse, personality issues, sexual problems, and physical or emotional abuse. If children of divorced parents are more likely to have lived in homes rife with financial problems and abuse, these children may not be as well off as other children at the time of divorce. Thus, any negative effects brought on by parental absence are added on to these original effects, potentially exaggerating any true father effect.

Studies that investigate children of deceased parents face a different set of self-selection biases, as mortality rates can covary among individuals within families (Curtis and Steele 1996; Guo 1993; Sear et al. 2002). Contextual conditions, such as pathogen exposure, community violence, and resource availability might have similar detrimental effects on both parents and children, leading to a general association in mortality. Genetic susceptibilities might be heritable from parent to child for congenital, autoimmune (Heward and Gough 1997), and infectious afflictions (Hill 1998). Heritable behavioral tendencies might promote health-risk behaviors that could increase morbidity and the frequency of accidents and/ or violence. This might be due to shared socioeconomic environment, genetic tendencies, or to children modeling their behavior after that of their parents.

\section{Assessing Self-Selection}

Ideally, studies of parent effects would include incomplete and complete households that were randomly distributed along all other confounding variables. To determine whether different causes of parental absence are more subject to selfselection, we perform analyses with data sets filtered by cause of parental absence and cause of child death. If a particular cause of parental death (e.g., by disease) is more heavily selfselected along variables that are linked to child mortality, then the effect size should be greater than it is when including all types.

Well-controlled studies often include variables that have 
also been found to be associated with child mortality, such as maternal age at birth, birth order, interbirth interval, family, and so on. Because the number and influence of confounding variables is ultimately unknowable, we investigate the summed effects of self-selected factors by testing for elevations in the mortality risks of children before parental death. If parental effects are partly due to the fact that both parents and children share an environment or constitution of greater risk, then there should be a general association between the mortality risks of offspring and parents, regardless of the order. Parental death should be predictive of children's mortality risk both before and after the event. We employ this strategy both with and without a random family term. If parent and child mortality rates covary in time independent of the impacts of parent absence (which would result in spurious parent effects), we should find no order effect even after controlling for family.

\section{Methods}

\section{Population}

The Tsimane are a forager-horticultural population living primarily along the Maniqui River and its tributaries in the Beni region of Bolivia. Approximately 9,000 individuals reside in some 80 villages, each consisting of multiple extended families (Gurven, Kaplan, and Zelada Supa 2007). A full examination of the Tsimane population is available in CA+ online supplement A.

\section{Demography}

Demographic interviews were conducted on all available adults in 21 villages, in which the reproductive histories of the interviewee and his or her parents and siblings were recorded. This resulted in the identification of 6,795 individuals for whom birth years and, if necessary, death years were estimated. Methods are described at length in Gurven, Kaplan, and Zelada Supa (2007). In consultation with a team physician (Dr. Daniel Eid Rodriguez), causes of death were deduced for $87.5 \%$ of the 1,483 deaths using a system based on the International Classification of Diseases, version 10 (WHO 1990). The demographic interviews were conducted between 2002 and 2005, and we have since been updating demographic information on individuals who continue to reside in our sample communities. For all analyses exploring parental death, individuals are excluded if demographic information was missing for either parent, if their parents divorced during the time period, or if the other parent (whose effect is not being tested) died. Therefore, mother-absent and father-absent children are compared only to the control group containing both parents. More details are available in CA+ supplement A.

\section{Data Analysis}

The effects of parental death on children's mortality rates were assessed using time-discrete event history analysis. The data were expanded so that each year for every individual was represented in the data set with parental absence status and control variables. We then used PROC NLMIXED in SAS 9.2 to fit mixed logistic regression models to assess the impact of parental absence. All analyses control for community area (upriver, downriver, Catholic mission, close to town, interior forest), sex, year of birth (to control for cohort effects), birth order, and age and include family identification (ID) as a random effect. Families are defined as members of a nuclear family residing within the same household.

\section{Results}

The results reported here replace those reported elsewhere using more limited samples and different inclusion/exclusion criteria (Sear and Mace 2008; Winking, Gurven, and Kaplan 2006). Furthermore, mortality hazards reported here differ from those reported in Gurven, Kaplan, and Zelada Supa (2007), as the sample used by Gurven et al. employed different inclusion/exclusion criteria. ${ }^{1}$

Figure 1 presents the survivorship of children depending on the timing of parental death (without controls). Those with both parents alive had a mortality rate of $9.1 \%$ in the first year of life. Mortality rates drop precipitously in the first 5 years, after which, they were never greater than $1 \%$. Within this sample, $80.1 \%$ lived to their fifteenth birthday. Survivorship of children whose mother has died is reduced, regardless of the age of mother's death. The effect is also evident among fathers, although it is less pronounced. Analyzing the sample of children with both parents alive $(N=3,889)$ with only the control variables resulted in significant effects for age $(\mathrm{OR}=1.081, P<.001)$, birth order $(\mathrm{OR}=1.168, P<$ $.001)$, and the random family term $(P<.001)$. The inclusion of the family term reduced the Akaike Information Criterion (a measure of model fit, with lower values indicating a better fit) from 6,100 to 4,115 .

\section{Parental Effect by Age at Time of Parent's Death}

Table 1 presents the results of time-discrete event history analyses exploring the effect of parental death on child mortality. The death of a mother in the first year of life has a substantial impact on the mortality of the infant, leading to nearly 169 times greater odds of death compared with the rate for children with living mothers (table $1 ; P<.001$ ). This remarkably high odds ratio (OR) is the result of controlling for family, as removing the random family term resulted in

1. Gurven, Kaplan, and Zelada Supa (2007) used criteria that best estimated true mortality rates, particularly in the first 5 years of life, whereas this study used criteria that would best allow for a testing of parental effects. For instance, cases were excluded in this analysis if parental information was incomplete, reducing the generational depth by 1. Furthermore, Gurven, Kaplan, and Zelada Supa (2007) included an estimated proportion of stillbirths and miscarriages to account for a likely underreporting of infant deaths. 

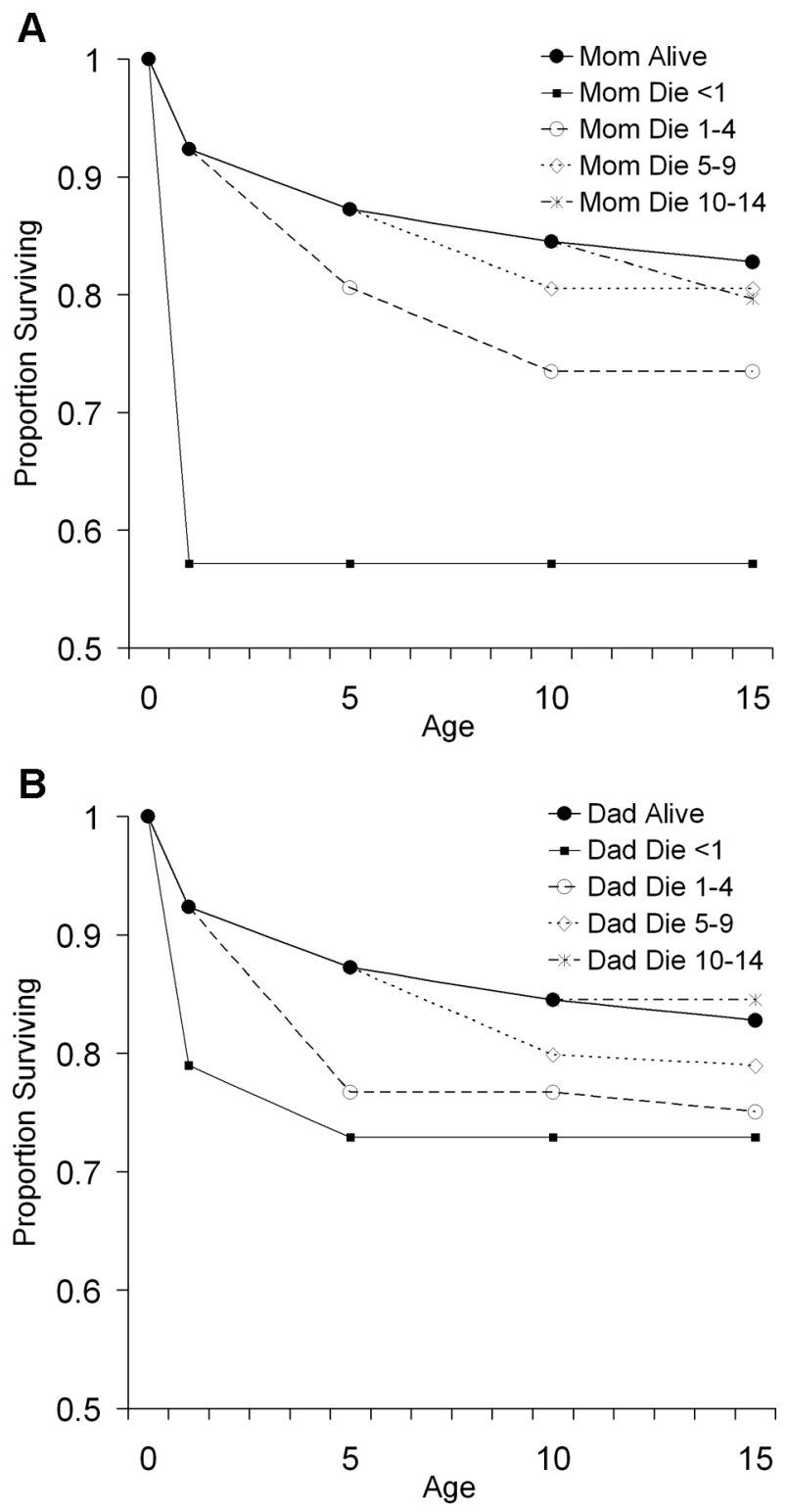

Figure 1. Kaplan-Meier plots of child mortality by age of mother death $(A)$ and age of father death $(B)$.

an odds ratio of $6.011(P<.001)$. There is a general trend toward a reduced effect of both early and recent maternal death as children age, and beyond 10 years of age, there is no evidence of such an effect. The bottom rows of table 1 include all ages from birth to the maximum year of the age interval. Again, there is a general decrease in the OR, suggesting a decreasing sensitivity to maternal death. For a number of age brackets, no child deaths were recorded in the parental death group, precluding the comparison of ORs.

Father death was significantly associated with child mortality risk for only one individual age category (table 1 ; ages $1-4$, OR $=3.614, P=.021)$. Similarly, the cumulative analysis for this age bracket (including the first year of life) sug- gests that father death is associated with 2.960 times the odds of death compared with the rate for those with living fathers $(P=.041)$. No significant associations were found beyond the age of 5 , although the OR and significance continue to decrease with increasing age.

\section{Parental Effects by Type of Death}

Different types of parental loss might be more or less problematic with regard to self-selection. Furthermore, if parental effects are driven by a correspondence between parental and child condition or shared environment, there should be a greater association between parental and child death of the same type. The distribution of causes of death for parents and children can be found in table A1 in CA+ supplement A. Unfortunately, most causes are too rare to allow for meaningful comparison, with disease being the major exception. Mortality risk is elevated following the disease-related death of a mother $(\mathrm{OR}=5.159, P=.002)$; however, the death of a parent by disease was not significantly associated with an increase in children's risk of dying by disease, which suggests a lack of self-selection along disease susceptibility (table 2).

Among the Tsimane, divorce is rare once a couple has children, which is partly why we focused on parent death. The impact of divorce was in the predicted direction, but nonsignificant $(\mathrm{OR}=1.817, P=.550)$. Because of the coding definitions, however, most of these individuals are children of divorced parents who each subsequently reproduced with others, possibly impacting the results.

\section{Parental Effect Before Parental Death}

The significance of the random family term suggests a correlation in mortality risks among family members. Yet deaths of family members might still be clumped in time, leading to the potential for self-selection even after controlling for family. Table 3 displays results of the analyses of the effect of parental death on the 5 years of mortality experience of children before the death of the parent. We include the results of models with and without a random term for family ID to illustrate the potential for self-selection. Cases were censored at 1 year before the death of the parent, the death of the child, when the child reached the maximum age of the age bracket, or 5 years before the death of the opposite parent. The models not controlling for family ID show a strong association between the future death of a parent and the mortality risk of children. These effects are largely eliminated by controlling for family, although one analysis approaches one-tailed significance (mother death, ages $0-9, \mathrm{OR}=.920, P=.103$ ).

The results of the analyses excluding a random family ID term suggest that there is a general association between parental and child mortality that is independent of parental presence. The fact that controlling for family largely eliminates this association suggests that the effect is felt by all children equally and does not vary temporally. 
Table 1. Mixed-effects logistic regression analysis of the effect of mother and father death on child death

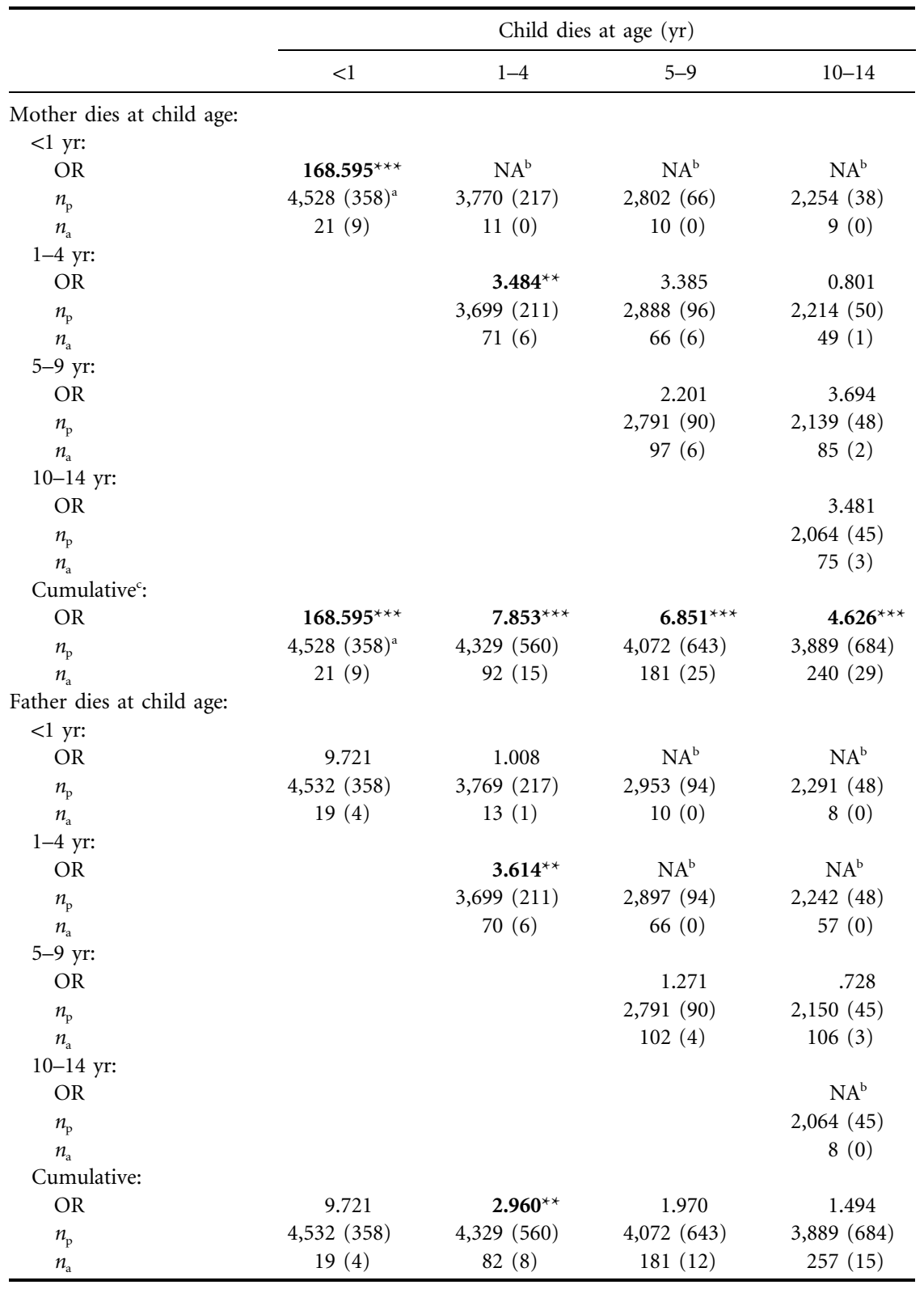

Note. All analyses control for age, sex, year born, birth order, community, and family. Analyses along the diagonals (except upper left cells) include parental death as a time-dependent variable. Those above the diagonal (and upper left cells) include parental death as a time-independent variable. Cumulative analyses include all years up to the maximum age (e.g., 0-4, 0-9, 0-15), with parental death as time dependent. All bold odds ratios (ORs) are significant at the $\alpha=0.05$ level.

${ }^{a}$ Reported $n$ is number of individuals, not risk years. Numbers within parentheses indicate the number of individuals within that group who died. $n_{\mathrm{p}}$ is number of individuals in the parentpresent group, and $n_{\mathrm{a}}$ is number of children in the parent-absent group.

${ }^{b}$ No deaths were recorded in the parent-absent group. NA = not applicable.

c Cumulative analyses include all years up to the maximum age (e.g., 0-4, 0-9, 0-15), with parental death as time dependent.

${ }^{*} P<.10$.

** $P<.05$.

*** $P<.01$. 
Table 2. Mixed-effects logistic regression analysis of the effect of parent death on child death by cause of death

\begin{tabular}{|c|c|c|c|c|}
\hline & \multicolumn{4}{|c|}{ Child dies } \\
\hline & All & Disease & Accident & Violence \\
\hline \multicolumn{5}{|c|}{ Mother dies: } \\
\hline \multicolumn{5}{|l|}{ All: } \\
\hline OR & 6.851 & 3.689 & 5.569 & $\mathrm{NA}^{\mathrm{b}}$ \\
\hline$P$ & $<.001$ & .034 & .214 & $\ldots$ \\
\hline$n_{\mathrm{p}}$ & $4,072(643)^{\mathrm{a}}$ & $3,898(469)$ & $3,471(42)$ & 3,445 \\
\hline$n_{\mathrm{a}}$ & $181(25)$ & $164(8)$ & $158(2)$ & $156(0)$ \\
\hline \multicolumn{5}{|c|}{ Disease: } \\
\hline OR & 5.966 & 3.412 & & \\
\hline$P$ & .001 & .134 & & \\
\hline$n_{\mathrm{p}}$ & $4,072(643)$ & $3,898(469)$ & & \\
\hline$n_{\mathrm{a}}$ & $90(14)$ & $81(5)$ & & \\
\hline \multicolumn{5}{|c|}{ Accident: } \\
\hline OR & 6.122 & & $\mathrm{NA}^{\mathrm{b}}$ & \\
\hline$P$ & .233 & & & \\
\hline$n_{\mathrm{p}}$ & $4,076(643)$ & & $3,471(42)$ & \\
\hline$n_{\mathrm{a}}$ & $15(2)$ & & $13(0)$ & \\
\hline \multicolumn{5}{|c|}{ Violence: } \\
\hline OR & $\mathrm{NA}^{\mathrm{c}}$ & & & $\mathrm{NA}^{\mathrm{c}}$ \\
\hline \multicolumn{5}{|l|}{$P$} \\
\hline$n_{\mathrm{p}}$ & $4,072(643)$ & & & 3,445 \\
\hline$n_{\mathrm{a}}$ & 0 & & & 0 \\
\hline \multicolumn{5}{|c|}{ Father dies: } \\
\hline \multicolumn{5}{|c|}{ All: } \\
\hline OR & 1.970 & 1.033 & 9.207 & $\mathrm{NA}^{\mathrm{d}}$ \\
\hline$P$ & .163 & .960 & .083 & $\cdots$ \\
\hline$n_{\mathrm{p}}$ & $4,072(643)$ & $3,898(469)$ & $3,471(42)$ & $3,445(16)$ \\
\hline$n_{\mathrm{a}}$ & $181(12)$ & $180(8)$ & $174(2)$ & $173(1)$ \\
\hline \multicolumn{5}{|c|}{ Disease: } \\
\hline OR & 1.554 & 0.879 & & \\
\hline$P$ & .543 & .879 & & \\
\hline$n_{\mathrm{p}}$ & $4,072(643)$ & $3,898(469)$ & & \\
\hline$n_{\mathrm{a}}$ & $79(7)$ & $77(5)$ & & \\
\hline \multicolumn{5}{|c|}{ Accident: } \\
\hline OR & 1.517 & & $\mathrm{NA}^{\mathrm{b}}$ & \\
\hline$P$ & .789 & & $\ldots$ & \\
\hline$n_{\mathrm{p}}$ & $4,072(643)$ & & $3,471(42)$ & \\
\hline$n_{\mathrm{a}}$ & $15(1)$ & & $14(0)$ & \\
\hline \multicolumn{5}{|c|}{ Violence: } \\
\hline OR & $\mathrm{NA}^{\mathrm{b}}$ & & & $\mathrm{NA}^{\mathrm{b}}$ \\
\hline$P$ & $\ldots$ & & & $\ldots$ \\
\hline$n_{\mathrm{p}}$ & $4,072(643)$ & & & 3,445 \\
\hline$n_{\mathrm{a}}$ & $18(0)$ & & & $18(0)$ \\
\hline \multicolumn{5}{|l|}{ Divorce: } \\
\hline OR & 1.817 & & & \\
\hline$P$ & .550 & & & \\
\hline$n_{\mathrm{p}}$ & $4,072(643)$ & & & \\
\hline$n_{\mathrm{a}}$ & $95(2)$ & & & \\
\hline
\end{tabular}

Note. All analyses control for age, sex, year born, birth order, community, and family and cover years $0-9$. All bold odds ratios (ORs) are significant at the $\alpha=0.05$ level.

${ }^{a}$ Reported $n$ is number of individuals, not risk years. Numbers within parentheses indicate the number of individuals within that group who died. $n_{\mathrm{p}}$ is number of individuals in the parent-present group, and $n_{\mathrm{a}}$ is number of children in the parent-absent group.

${ }^{b}$ No deaths were recorded in the parent-absent group. NA = not applicable.

${ }^{c}$ There were no mothers who died due to violence.

d The Hessian matrix was not positive definite due to the small number of child deaths.

\section{Discussion}

Among the Tsimane, it appears that both mothers and fathers have an impact on child survival and that these effect are most evident during the first years of life. The impact on a child of a mother's death is far greater than that of a father's, with the greatest impact coming from the death of a mother in the first year of life. Overall, the effects of parental death decrease with the age of the child, with no effects being detected after age 10. Furthermore, greater similarity in mortality rates within families is evidenced by the fact that the random family term was significant in all analyses reported here.

Breaking the sample down by type of death did not lead to any obvious indication of self-selection. We included accidental death, because it seemed the best candidate for a randomly distributed variable. For instance, a cause of death ideal for this exercise would be one that was not heavily dependent on variance in environment, condition, or behavior, such as a tree fall. While such accidental deaths are rare, studies involving large populations might be able to employ this strategy to assess the impact of parental death due to vehicle accident, for example.

In order to assess the total impact of shared environment, condition, and inherited predispositions, we assessed the association of child death with future parental death. Without controlling for the random effects of family, whether or not a parent died within the next 5 years was predictive of the mortality risk the child faced. Although previous kin- and parent-effect studies often include numerous control variables in an attempt to isolate the impact of the presence/absence of a particular kin member, perhaps one of the best indicators of the baseline hazard that a child is subject to is whether or not a parent has died.

Controlling for family as a random term largely eliminates this self-selection bias, suggesting that mortality rates covary between a parent and all of his/her children equally. This would not be the case for temporally varying factors, such as food shortfalls, epidemics, or varying violence levels. For instance, a temporary famine might increase the risk of death for a father and his dependent children, although older children may have already moved elsewhere (or at least would not be included in the study as a child). The result of controlling for family implies that either $(a)$ environmental or condition-related variables are important but temporally invariant or $(b)$ inherited differences are leading to differing mortality rates. It is possible that child death might lead to greater likelihood of parental death due to emotional or financial costs associated with the loss of a child. Offspring death is more commonplace among the Tsimane, however, and perhaps less traumatic. ${ }^{2}$ Furthermore, chronic childhood

2. One conversation with an older Tsimane woman led to the discussion of the 6 of her 12 children who had died. She listed the names while counting on her fingers so as to not forget one, although she had to struggle to recall the last name. She spoke with a degree of equanimity that would likely be considered detachedly stoic to most Western mothers. 
Table 3. Mixed-effects logistic regression analysis of the effect of future parental death on previous child death

\begin{tabular}{|c|c|c|c|c|}
\hline & \multicolumn{2}{|c|}{$\begin{array}{l}\text { Without random family term; } \\
\text { child dies at age (yr) }\end{array}$} & \multicolumn{2}{|c|}{$\begin{array}{l}\text { With random family term; } \\
\text { child dies at age (yr) }\end{array}$} \\
\hline & $0-4$ & $0-9$ & $0-4$ & $0-9$ \\
\hline \multicolumn{5}{|c|}{ Mother dies within $5 \mathrm{yr}$ : } \\
\hline OR & 2.122 & 2.438 & 1.461 & 2.510 \\
\hline$P$ & .002 & $<.001$ & .421 & .103 \\
\hline$n_{\mathrm{p}}$ & $3,951(509)^{\mathrm{a}}$ & $3,720(555)$ & $3,951(509)$ & $3,720(555)$ \\
\hline$n_{\mathrm{a}}$ & $131(19)$ & $194(26)$ & $131(19)$ & $194(26)$ \\
\hline \multicolumn{5}{|c|}{ Father dies within $5 \mathrm{yr}$ : } \\
\hline OR & 1.605 & 2.035 & 1.503 & 1.003 \\
\hline$P$ & .088 & .001 & .352 & .994 \\
\hline$n_{\mathrm{p}}$ & $3,937(514)$ & $3,840(566)$ & $3,937(514)$ & $3,840(566)$ \\
\hline$n_{\mathrm{a}}$ & $139(15)$ & $253(26)$ & $139(15)$ & $253(26)$ \\
\hline
\end{tabular}

Note. All analyses control for age, sex, year born, birth order, and community. All bold odds ratios (ORs) are significant at the $\alpha=0.05$ level.

${ }^{\text {a }}$ Reported $n$ is number of individuals, not risk years. Numbers within parentheses indicate the number of individuals within that group who died.

illnesses are rare, as health care is typically prohibitively costly and distant.

These results call into question previous studies that did not take into account the effect of family. For some cases, however, controlling for family may not be warranted. In some populations, there may not be substantial variation in mortality rates between families after controlling for other factors (Borgerhoff Mulder 2007). In postdemographic transition samples, there may be a substantial portion of families that include only one child, making interpretation of family effects more difficult. An alternative to including a random family term might be to take the ratio of the impact of parent death on the mortality risk of children 5 years before the death occurred to that during the 5 years after the death occurred. For instance, performing this calculation for ages 0-4 years with this data set (and removing the random family ID terms) yields ratios of 1.827 (the difference between the two coefficients approached significance; $P=.11$ ) and 1.735 for father death $(P=.19)$.

While maternal death appears to be universally detrimental to child survival cross-culturally, the impact of father death is much more variable. If self-selection is exaggerating these effects, the impact of paternal death might be even less robust. If men truly are the outstanding fathers of the primate world, why are children not consistently faring substantially worse after their death? One explanation is that the benefits of men's care are not realized via mortality reduction. Fathers' investments can reduce the interbirth intervals of their wives (Gettler 2010) and enhance the future social competitiveness of their children (Anderson, Kaplan, and Lancaster 1999). An alternative explanation is that the inconsistency of father effects is due to the overall flexibility of kin support. Concerned kin members can boost their own levels of involvement to fill a child-care deficit (Deleire and Kalil 2002; Winking 2006). Grandparents might base residence patterns on which chil $\rightarrow$ dren are in the most need (Blurton Jones, Hawkes, and O'Connell 2005). Among the Tsimane, widowed and divorced women (and their children) typically reside with their parents until remarriage. In contrast, maternal care may be less replaceable, particularly in the first years of children's lives.

The limitations of this study are largely a result of small sample sizes and the imprecision of retrospective interview data (particularly when working with a population without formal records). Despite this, our exploration of self-selection with this data set gives us confidence in the reported parent effects among the Tsimane. It also revealed the importance of somehow controlling for family effects. Despite the potential for self-selection along numerous pathways, perhaps the most convincing evidence that parental absence studies are capturing something real is the fact that maternal loss studies consistently report significant effects while those exploring paternal loss or grandparental presence are much more variable. These studies clearly play a role in the exploration of the benefits of having two caretakers and the costs of marital dissolution, and they are very important to the study of the evolution of humans' unique mating system and reproductive patterns. The results, however, need to be interpreted with consideration for self-selection issues outlined in this study. We suggest that future parent-absent studies include more continuous measures of parental investment and child wellbeing, as well as explorations of the reactionary behaviors of alternative caretakers.

\section{References Cited}

Amato, P. R., and D. Previti. 2003. People's reasons for divorcing: gender, social class, the life course, and adjustment. Journal of Family Issues 24:602-626.

Anderson, K. G., H. Kaplan, and J. Lancaster. 1999. Paternal care by 
genetic fathers and stepfathers I: reports from Albuquerque men. Evolution and Human Behavior 20:405-431.

Becher, H., O. Muller, A. Jahn, A. Gbangou, G. Kynast-Wolf, and B. Kouyate. 2004. Risk factors of infant and child mortality in rural Burkina Faso. Bulletin of the World Health Organization 82:265273.

Blurton Jones, N., K. Hawkes, and J. F. O’Connell. 2005. Older Hadz: $\rightarrow$ men and women as helpers. In Hunter-gatherer childhoods. B. S. Hewlett and M. E. Lamb, eds. Pp. 214-236. New Brunswick, NJ: Transaction.

Blurton Jones, N. G., F. Marlowe, K. Hawkes, and J. F. O'Connell. 2000. Paternal investment and hunter-gatherer divorce rates. In Adaptation and human behavior: an anthropological perspective. Lee Cronk, Napolean Chagnon, and William Irons, eds. Pp. 69-90. New York: Aldine.

$\rightarrow$ Borgerhoff Mulder, M. 2007. Hamilton's rule and kin competition: the Kipsigis case. Evolution and Human Behavior 28:299-312.

$\rightarrow$ Curtis, S. L., and F. Steele. 1996. Variations in familial neonatal mor tality risks in four countries. Journal of Biosocial Science 28:141159.

$\rightarrow$ Deleire, T., and A. Kalil. 2002. Good things come in threes: singleparent multigenerational family structure and adolescent adjust ment. Demography 39:393-413.

$\rightarrow$ Gettler, L. 2010. Direct male care and hominin evolution. American Anthropologist 112:7-21.

$\rightarrow$ Guo, G. 1993. Use of sibling data to estimate family mortality effects in Guatemala. Demography 30:15-32.

$\rightarrow$ Gurven, M., H. Kaplan, and A. Zelada Supa. 2007. Mortality experience of Tsimane Amerindians: regional variation and tempora ${ }^{1}$ trends. American Journal of Human Biology 19:376-398.

$\rightarrow$ Hagen, E. H., R. H. Hames, N. M. Craig, M. T. Lauer, and M. E Price. 2001. Parental investment and child health in a Yanomamo village suffering short-term food stress. Journal of Biosocial Science 33:505-528.

Hames, R., W. J. Oliver, and N. A. Chagnon. 2005. Growth, development, and health of Yanomamö orphans in relation to parental loss and kinship. Paper presented at the 17th annual meeting of the Human Behavior and Evolution Society, Austin, TX, June 15.

Heward, J., and S. C. L. Gough. 1997. Genetic susceptibility to the development of autoimmune disease. Clinic Science 93:479-491.

$\rightarrow$ Hill, A. V. S. 1998. The immunogenetics of human infectious diseases. Annual Review of Immunology 16:593-617.

$\rightarrow$ Hogberg, U., and G. Brostrom. 1985. The demography of maternal mortality: 7 Swedish parishes in the 19th century. International Journal of Gynecology \& Obstetrics 23:489-497.

Hurtado, A. M., and K. R. Hill. 1992. Paternal effect on offspring survivorship among Ache and Hiwi hunter-gatherers: implications for modeling pair-bond stability. In Father-child relations: cultural and biosocial contexts. B. S. Hewlett, ed. Pp. 31-55. Chicago: Aldine.

Kaplan, H. 1994. Evolutionary and wealth flows theories of fertility: empirical tests and new models. Population and Development Review 20:753-791.

$\rightarrow$ Kitson, G. C., K. B. Babri, and M. J. Roach. 1985. Who divorces and why: a review. Journal of Family Issues 6:255-293.

Lamb, M. E. 1997. Fathers and child development: an introductory overview and guide. In The role of the father in child development. 3rd edition. M. E. Lamb, ed. Pp. 1-18. New York: Wiley.

$\rightarrow$ Lee, R. D., and K. L. Kramer. 2002. Children's economic roles in the Maya family life cycle: Cain, Caldwell and Chayanov revisited. Population and Development Review 28:475-499.

Leonetti, D. L., D. C. Nath, N. S. Hemam, and D. B. Neill. 2004. Do women really need marital partners for support of their reproductive success? the case of the matrilineal Khasi of N. E. India. Research in Economic Anthropology 23:151-174.

Sear, R., and R. Mace. 2008. Who keeps children alive? a review of the effects of kin on child survival. Evolution and Human Behavior 29:1-18.

Sear, R., R. Mace, and I. A. McGregor. 2000. Maternal grandmothers improve the nutritional status and survival of children in rural Gambia. Proceedings of the Royal Society B: Biological Sciences 267: 1641-1647.

Sear, R., F. Steele, I. A. McGregor, and R. Mace. 2002. The effects of kin on child mortality in rural Gambia. Demography 39:43-63.

$\rightarrow$ Sellen, D. W., and D. B. Smay. 2001. Relationship between subsistence and age at weaning in "preindustrial" societies. Human Nature 12: 47-87.

Tronick, E. Z., G. A. Morelli, and S. Winn. 1987. Multiple caretaking of Efe (Pygmy) infants. American Anthropologist 89:96-106.

WHO (World Health Organization). 1990. International classification of diseases. Version 10. Geneva: World Health Organization.

Winking, J. 2006. Are men that bad as fathers? the role of men's investments. Social Biology 53:100-115.

Winking, J., M. Gurven, and H. Kaplan. 2006. Measuring impacts of fathers among the Tsimane of Bolivia. Paper presented at the 18th annual meeting of the Human Behavior and Evolution Society, Philadelphia, PA, June 7-11. 